\title{
Comparison of active renin concentration and plasma renin activity for the diagnosis of primary hyperaldosteronism in patients with an adrenal mass
}

\author{
Nicole Unger ${ }^{1}$, Ingo Lopez Schmidt ${ }^{1}$, Christian Pitt ${ }^{4}$, Martin K Walz ${ }^{4}$, Thomas Philipp ${ }^{2}$, Klaus Mann ${ }^{1,3}$ and \\ Stephan Petersenn ${ }^{1}$ \\ ${ }^{1}$ Division of Endocrinology, Medical Center, ${ }^{2}$ Division of Nephrology and Hypertension, Medical Center, ${ }^{3}$ Department of Clinical Chemistry, \\ University of Essen and ${ }^{4}$ Department of Surgery and Centre of Minimally Invasive Surgery, Kliniken Essen-Mitte, Essen, Germany \\ (Correspondence should be addressed to S Petersenn, Division of Endocrinology, Medical Center, University of Essen, Hufelandstr. 55, 45122 Essen, \\ Germany; Email: stephan.petersenn@uni-essen.de)
}

\begin{abstract}
Objective: Plasma aldosterone concentration (PAC) to plasma renin activity (PRA) ratio is an established screening test for primary hyperaldosteronism. Due to the increased recognition of adrenal incidentalomas, reliable parameters are required. Determination of active renin concentration (ARC) in contrast to PRA offers advantages with regard to processing and standardization. The present study compared PRA and ARC under random conditions to establish thresholds for the diagnosis of primary hyperaldosteronism.

Design and methods: Fifty patients with various adrenal tumors, including ten patients with aldosterone-secreting adrenal adenomas, as well as ten hypertensive patients and 23 normotensive volunteers were studied. PAC and PRA were measured by radioimmunoassay. ARC was determined by an immunoluminometric assay.

Results: Receiver operating curve (ROC) analysis suggested a PAC to ARC ratio threshold of 90 $((\mathrm{ng} / \mathrm{l}) /(\mathrm{ng} / \mathrm{l}))$ (sensitivity $100 \%$, specificity $98.6 \%)$ and a ratio threshold of 62 by additional consideration of PAC $\geq 200 \mathrm{ng} / \mathrm{l}$ (sensitivity 100\%, specificity 100\%) for the diagnosis of aldosterone-secreting adrenal adenomas.

Conclusions: A PAC to ARC ratio of $\geq 62$ in patients with PAC levels $\geq 200 \mathrm{ng} / \mathrm{l}$ is a reliable screening method for primary hyperaldosteronism in patients with an aldosterone-producing adenoma under random conditions. Because of its advantages with regard to probe processing and its independence from endogenous angiotensinogen levels, ARC may be preferred to PRA.
\end{abstract}

European Journal of Endocrinology 150 517-523

\section{Introduction}

Primary hyperaldosteronism is classically characterized by a combination of hypertension, hypokalemia, suppressed renin and an elevated non-suppressible plasma aldosterone concentration. Measurement of these single parameters does not allow a reliable diagnosis. Normokalemia is noted in patients with primary hyperaldosteronism $(1-3)$, as well as suppressed renin in hypertensive patients $(4,5)$. Due to improved methods in computed tomography (CT) or magnetic resonance imaging (MRI), adrenal incidentalomas are increasingly found. Accurate parameters to distinguish aldosterone-secreting adrenal adenomas from other functioning or non-functioning adrenal masses are therefore required.

The plasma aldosterone concentration (PAC) to plasma renin activity (PRA) ratio was suggested as a screening tool for the diagnosis of primary hyperaldosteronism (1). In contrast to single measurement of either PAC or PRA, the PAC to PRA ratio seems to be independent of diurnal and day-to-day variations, salt intake and diuretics. It was demonstrated as a reliable and convenient screening tool for ambulatory conditions, independent of body posture (6). However, a recent study revealed a low reproducibility of the ratio in patients with an aldosterone-producing adrenal adenoma under random conditions (7). PRA is determined by radioimmunological measurement of angiotensin-1 generated from angiotensinogen during in vitro incubation with plasma renin. However, determination is limited to physiological angiotensinogen levels. Conditions with decreased angiotensinogen levels (e.g. liver cirrhosis, severe cardiac failure) result in the underestimation of renin $(8,9)$. In contrast, estrogen treatment increases angiotensinogen levels, resulting in an overestimation of renin $(10,11)$. The lack of standardization is another methodical disadvantage. Processing of plasma samples, especially in regard to incubation time, $\mathrm{pH}$ and dilution varies among different 
Table 1 Clinical characterization of the population studied. Values are means \pm S.D.

\begin{tabular}{|c|c|c|c|c|}
\hline Diagnosis & No. of patients & Age (years) & Sex (male/female) & Tumor size $(\mathrm{cm})$ \\
\hline Aldosterone-secreting adenoma & 10 & $51.4 \pm 13.3$ & $3 / 7$ & $1.8 \pm 0.6$ \\
\hline Cortisol-secreting adenoma & 7 & $43.7 \pm 12.5$ & $0 / 7$ & $3.3 \pm 0.8$ \\
\hline Pheochromocytoma & 12 & $49.3 \pm 16.5$ & $6 / 6$ & $3.8 \pm 2.5$ \\
\hline Non-functioning adrenal mass (NFM) & 21 & $51.9 \pm 12.6$ & $10 / 11$ & $3.9 \pm 2.6$ \\
\hline Essential hypertension & 10 & $41.6 \pm 11.4$ & $6 / 4$ & na \\
\hline Healthy volunteers & 23 & $34.2 \pm 12.2$ & $10 / 13$ & na \\
\hline Total & 83 & $44.6 \pm 14.6$ & $35 / 48$ & na \\
\hline
\end{tabular}

na, not available.

laboratories. In patients with suppressed renin, the ratio is clearly dependent on the lower detection limit. An assay sensitivity of $0.5 \mathrm{ng} / \mathrm{ml}$ per hour for a PRA assay compared with $0.1 \mathrm{ng} / \mathrm{ml}$ per hour for another assay results in an unequivocal lower PAC to PRA ratio.

To avoid these disadvantages, generation of monoclonal antibodies against active renin allowed direct measurement of active renin concentration (ARC) independent from angiotensinogen levels. Standardization of ARC measurement by calibration against a WHO standard enables improved comparability among different laboratories. The present study compared PRA and ARC under random conditions to investigate the use of ARC for the diagnosis of primary hyperaldosteronism in patients with aldosterone-producing adenomas.

\section{Materials and methods}

\section{Subjects}

Fifty patients with a current adrenal mass were grouped into four categories: ten aldosterone-secreting adrenal adenomas; seven cortisol-secreting adrenal adenomas (one subclinical and six overt Cushing's syndromes), 12 pheochromocytomas; and 21 non-functioning adrenal masses (17 non-functioning adenomas, two cysts, one metastasis of bronchial carcinoma, one myeololypoma). The diagnoses were made preoperatively by appropriate biochemical parameters in combination with evidence of an adrenal mass on CT or MRI. Primary hyperaldosteronism due to an adrenal adenoma was diagnosed by a plasma aldosterone to renin activity ratio $\geq 300(\mathrm{ng} / \mathrm{l}$ to $\mathrm{ng} / \mathrm{ml}$ per $\mathrm{h}$ ) and $\mathrm{PAC} \geq 200 \mathrm{ng} / \mathrm{l}$ (12) and in part confirmed by increased urinary aldosterone-18-glucuronide excretion, saline infusion test, adrenal vein sampling and/or postural stimulation test. Four patients showed a normokaliemic hyperaldosteronism. In these ten patients, CT or MRI revealed a unilateral adrenal mass. Clinical follow-up was carried out in five patients demonstrating a normalized PAC to PRA ratio postoperatively. Because of the limitations of the screening parameters, patients with mild hyperaldosteronism might have been undiagnosed.

Except for five non-functioning adenomas with a size less than $3 \mathrm{~cm}$, all adrenal masses were subsequently removed. The diagnosis was postoperatively confirmed by histological and immunohistochemical examinations as well as clinical follow-up.

Controls included ten patients with essential hypertension and 23 healthy normotensive volunteers taking an ad libitum sodium diet. In patients with essential hypertension, endocrine disorders were excluded by the following tests: primary hyperaldosteronism was excluded by a normal PAC and PAC to PRA ratio; Cushing's syndrome was investigated by midnight plasma cortisol levels and a dexamethasone suppression test; pheochromocytoma was excluded by normal metanephrines and urinary catecholamines. Furthermore, renal artery stenosis was excluded by MRI and/or duplex ultrasound in nine of ten patients. In total, 83 subjects were included in this prospective study (pertinent data are given in Table 1).

At the time of investigation, patients with an aldosterone-secreting adrenal adenoma, patients with pheochromocytoma, and patients with hypertension were on various antihypertensive medications, as well as nine hypertensive patients with non-functioning adrenal adenomas. Three of ten patients with an aldosterone-producing adenoma received spironolactone preoperatively (Table 2).

Blood samples were drawn from patients in an upright body position from a forearm vein between $0800 \mathrm{~h}$ and $0900 \mathrm{~h}$. The study protocol was approved by the local ethical committee and informed consent was given by all patients.

\section{Assays}

PAC was measured by RIA (Byk \& DiaSorin, Dietzenbach, Germany). The normal range in an upright position was $100-350 \mathrm{ng} / \mathrm{l}$. Assay sensitivity was $50 \mathrm{ng} / \mathrm{l}$ and assay variability was determined by within-assay coefficients of variation (CV) of $11.2 \%$ for $73 \mathrm{ng} / \mathrm{l}$ and $8.2 \%$ for $308 \mathrm{ng} / \mathrm{l}$ and between-assay $\mathrm{CV}$ values of $17.7 \%$ for $73 \mathrm{ng} / \mathrm{l}, 10.4 \%$ for $208 \mathrm{ng} / \mathrm{l}$ and $6.6 \%$ for $454 \mathrm{ng} / \mathrm{l}$.

PRA was also determined by RIA (Byk \& DiaSorin). The normal range in an upright position was $1.8-$ $6.3 \mathrm{ng} / \mathrm{ml}$ per hour. Assay sensitivity was $0.1 \mathrm{ng} / \mathrm{ml}$ per hour. Within-assay $\mathrm{CV}$ values were $7.5 \%$ for $0.17 \mathrm{ng} / \mathrm{ml}$ per hour, $5.4 \%$ for $8.8 \mathrm{ng} / \mathrm{ml}$ per hour 
Table 2 Medication in patients with hypertension.

\begin{tabular}{|c|c|c|c|c|c|}
\hline Medication & $\begin{array}{c}\text { Aldosterone-secreting } \\
\text { adenoma }\end{array}$ & $\begin{array}{l}\text { Cortisol-secreting } \\
\text { adenoma }\end{array}$ & Pheochromocytoma & NFM & $\begin{array}{c}\text { Essential } \\
\text { hypertension }\end{array}$ \\
\hline$\alpha$ blockers & 2 & - & 6 & 1 & 1 \\
\hline$\beta$ blocker & 6 & 4 & 1 & 3 & 7 \\
\hline Ca-channel blocker & 4 & 2 & 2 & 5 & 7 \\
\hline ACE inhibitors & 4 & 1 & 2 & 4 & 3 \\
\hline AT1-receptor antagonists & - & 2 & 1 & 2 & 1 \\
\hline Diuretics & 2 & 1 & 1 & 2 & 1 \\
\hline Clonidin & 1 & - & - & 1 & 1 \\
\hline Spironolactone & 3 & - & - & - & - \\
\hline
\end{tabular}

$\mathrm{ACE}$, angiotensin converting enzyme; AT1, angiotensin-A.

and $9.9 \%$ for $13.5 \mathrm{ng} / \mathrm{ml}$ per hour. Between-assay CV values were $7.7 \%$ for $2.6 \mathrm{ng} / \mathrm{ml}$ per hour, $8.1 \%$ for $8.6 \mathrm{ng} / \mathrm{ml}$ per hour and $11.5 \%$ for $13.0 \mathrm{ng} / \mathrm{ml}$ per hour.

ARC was determined in EDTA-treated plasma by a two-site chemiluminescent enzyme immunometric assay with a functional sensitivity of $1 \mathrm{ng} / \mathrm{l}$ (Nichols Institute Diagnostics, Bad Nauheim, Germany). The normal range in an upright position was $2.1-26 \mathrm{ng} / \mathrm{l}$ by calibration against a WHO standard. Betweenassay $\mathrm{CV}$ values were $10-14 \%$ for $3.9 \mathrm{ng} / \mathrm{l}, 3.4-4 \%$ for $20 \mathrm{ng} / \mathrm{l}$ and $3 \%$ for $125 \mathrm{ng} / \mathrm{l}$. Within-assay $\mathrm{CV}$ values were $7.2 \%$ for $4.9 \mathrm{ng} / \mathrm{l}, 4.0 \%$ for $10 \mathrm{ng} / \mathrm{l}, 3.8 \%$ for $49 \mathrm{ng} / \mathrm{l}$ and $3.7 \%$ for $124 \mathrm{ng} / \mathrm{l}$.

The ratio of PAC to PRA and PAC to ARC was calculated for all subjects. In samples with suppressed PRA and ARC the lower detection limit of the respective assay was used for calculation.

\section{Statistical evaluation}

Results are expressed as means \pm S.E.M. GraphPad Prism 3.0 (GraphPad Software Inc., San Diego, CA, USA) was used for statistical analyses. A Spearman's rank correlation analysis was used to determine the relationship between variables. The Kruskal-Wallis test, followed by Dunn's multiple comparison test, was performed where appropriate. Receiver operating curve (ROC) analyses were obtained using MedCalc 6.16 software (MedCalc Software, Mariakerke, Belgium).

\section{Results}

\section{PAC to PRA ratio}

PAC to PRA ratio was $3570 \pm 262((\mathrm{ng} / \mathrm{l}) /(\mathrm{ng} / \mathrm{ml}$ per $\mathrm{h}))$ (means \pm S.D.) in patients with primary hyperaldosteronism and $271 \pm 32((\mathrm{ng} / \mathrm{l}) /(\mathrm{ng} / \mathrm{ml}$ per $\mathrm{h}))$ in the remaining 73 subjects. Ratios for each subgroup are shown in Table 3. The ratio was significantly higher in patients with primary hyperaldosteronism than in pheochromocytomas, cortisol-secreting adenomas, non-functioning adrenal masses, hypertensive patients and healthy volunteers, as analyzed by KruskalWallis and Dunn's multiple comparison test. ROC analysis suggested a ratio threshold value of 680 (sensitivity $100 \%$, specificity $91.8 \%$, area under the curve $(\mathrm{AUC})=0.992)$ for the diagnosis of primary hyperaldosteronism. All patients with primary hyperaldosteronism fulfilled this condition, while 66 of the remaining 73 subjects were below this ratio. However, seven subjects $(10.6 \%)$ were falsely classified as having primary hyperaldosteronism. With the additional consideration of $\mathrm{PAC} \geq 200 \mathrm{ng} / \mathrm{l}$ for the diagnosis of primary hyperaldosteronism, ROC analysis suggested a threshold ratio of 330 (sensitivity 100\%, specificity $100 \%$, AUC $=1.0$ ), as expected by the criteria used for the diagnosis of hyperaldosteronism. Under this condition, none of the control subjects were positively screened for primary hyperaldosteronism (Fig. 1).

\section{Correlation of PRA to ARC}

Spearman's test demonstrated a significant correlation for the PAC to PRA and PAC to ARC ratio with $r=0.91$ $(P<0.001)$ (data not shown).

\section{PAC to ARC ratio}

PAC to ARC ratio was $388 \pm 292((\mathrm{ng} / \mathrm{l}) /(\mathrm{ng} / \mathrm{l}))$ in patients with primary hyperaldosteronism and $24.1 \pm 3.4$ in 29 control subjects (Table 3). The ratio was significantly higher in primary hyperaldosteronism than in all other groups. ROC analysis suggested a ratio threshold value of 90 (sensitivity $100 \%$, specificity $98.6 \%, \mathrm{AUC}=0.996$ ) for the diagnosis of primary hyperaldosteronism. Two control subjects $(2.7 \%)$ were above that threshold. With additional consideration of PAC $>200 \mathrm{ng} / \mathrm{l}$, ROC analysis revealed a threshold ratio of 62 with a similar sensitivity, but an increased specificity of $100 \%(A U C=1)$. Under this condition, the control subjects remained below the threshold (Fig. 2).

\section{Discussion}

This study compared the ARC and PRA for the diagnosis of primary hyperaldosteronism. We did not include 
Table 3 PAC, PRA and ARC levels as well as PAC to PRA ratios and PAC to ARC ratios for the six subgroups. Values are means \pm S.D.

\begin{tabular}{|c|c|c|c|c|c|}
\hline Diagnosis & $\begin{array}{l}\text { PAC } \\
(\mathrm{ng} / \mathrm{l})\end{array}$ & $\begin{array}{c}\text { PRA } \\
(\mathrm{ng} / \mathrm{ml} \text { per h) }\end{array}$ & $\begin{array}{l}\text { ARC } \\
(\mathrm{ng} / \mathrm{l})\end{array}$ & $\begin{array}{l}\text { PAC to PRA ratio } \\
(\mathrm{ng} / \mathrm{l}) /(\mathrm{ng} / \mathrm{ml} \text { per } \mathrm{h})\end{array}$ & $\begin{array}{c}\text { PAC to ARC ratio } \\
(\mathrm{ng} / \mathrm{l}) /(\mathrm{ng} / \mathrm{l})\end{array}$ \\
\hline Aldosterone-secreting adenoma & $544 \pm 328$ & $0.2 \pm 0.1$ & $1.7 \pm 1.0$ & $3570 \pm 262$ & $388 \pm 292$ \\
\hline Cortisol-secreting adenoma & $126 \pm 117$ & $1.6 \pm 1.8$ & $14.8 \pm 15.0$ & $163 \pm 211^{\star *}$ & $16.0 \pm 19.1^{\star *}$ \\
\hline Pheochromocytoma & $128 \pm 60$ & $1.5 \pm 1.2$ & $20.0 \pm 15.4$ & $317 \pm 525^{\star \star}$ & $19.0 \pm 24.8^{\star \star}$ \\
\hline NFM & $159 \pm 170$ & $1.6 \pm 2.9$ & $20.4 \pm 35.3$ & $291 \pm 296$ ** & $27.4 \pm 39.2^{\star \star}$ \\
\hline Essential hypertension & $141 \pm 121$ & $1.2 \pm 1.9$ & $18.5 \pm 36.5$ & $409 \pm 402^{*}$ & $33.2 \pm 30.3^{\star}$ \\
\hline Healthy volunteers & $161 \pm 121$ & $1.1 \pm 1.2$ & $12.7 \pm 10.4$ & $202 \pm 148^{\star \star}$ & $22.2 \pm 22.4^{\star *}$ \\
\hline
\end{tabular}

${ }^{\star} P<0.05,{ }^{* \star} P<0.001$ in relation to aldosterone-producing adenomas.

patients with bilateral hyperplasia with potentially lower levels of aldosterone. Our aim was to establish an accurate screening tool for the diagnosis of adrenal masses with special regard to ambulatory conditions. Blood was obtained from patients in an upright posture after random activity.

Diagnosis of primary hyperaldosteronism was established following the recommendations of a recent NIH consensus statement (12). Without consideration of a threshold for PAC, our ROC analysis suggested a PAC to PRA ratio $\geq 680$ with a sensitivity of $100 \%$ and a reduced specificity of $91.8 \%$. Various threshold values between 200 and 1000 are mentioned in the literature $(1,2,12-16)$. In our study, specificity decreased to $86 \%$ for a ratio of $\geq 500,70 \%$ for a ratio of $\geq 330$ and $62 \%$ for a ratio of $\geq 200$, while sensitivity remained unchanged.

The influence of antihypertensive medication on the accuracy of PAC to PRA and ARC ratios respectively is controversial. Because of our aim of establishing a screening tool in ambulatory settings we favored the continuation of antihypertensive medication. Gallay et al. (2) showed no significant correlation between different values of the PAC to PRA ratio and numbers or types of antihypertensive medications. However, Seifarth et al. (17) found some influence of antihypertensive medication on the PAC to ARC ratio. $\beta$ blockers significantly increased the ratio, while angiotensin converting enzyme (ACE) inhibitors, aldosterone antagonists and $\mathrm{AT}_{1}$ receptor antagonists significantly decreased the ratio. Two other studies of hypertensive patients on antihypertensive medication revealed a ratio threshold value of 270 (sensitivity 93\%) and 1000 (sensitivity 100\%) respectively, without consideration of elevated PAC or suppressed PRA $(2,13)$.

In contrast, several studies discontinued antihypertensive treatment in hypertensive patients revealing a PAC to PRA ratio range of 200 to $500(1,14-16)$. The ratios are nearly similar to those in studies with continued antihypertensive medication.

Comparing the results of PRA and ARC, we have established a threshold for the PAC to ARC ratio. A threshold value of 90 provided a high sensitivity and specificity for the diagnosis of primary hyperaldosteronism. By considering PAC $\geq 200 \mathrm{ng} / \mathrm{l}$, a ratio threshold of
62 was established with improved specificity. Another study examined the determination of ARC for the diagnosis of primary hyperaldosteronism (18). Trenkel et al. (18) studied 17 patients with primary hyperaldosteronism (nine adrenal adenomas, eight idiopathic hyperaldosteronism), 146 hypertensive patients on various medication and 37 normotensive subjects. Primary hyperaldosteronism was diagnosed by a PAC to PRA ratio $\geq 200$ and subsequent tests. $A$ PAC to ARC ratio cut-off value of 50 revealed a sensitivity of $89 \%$ and a specificity of $96 \%$. In contrast to our study, sensitivity decreased to $84 \%$ and specificity increased to $100 \%$ by considering a PAC $\geq 200 \mathrm{ng} / \mathrm{l}$ as an additional criterion. The high proportion of idiopathic hyperaldosteronism, which is probably susceptible for lower aldosterone levels, might explain the lower threshold. Controls were not diagnosed by determination of PAC to PRA ratio, possibly resulting in an underestimation of primary hyperaldosteronism.

Automated methods for the determination of ARC provide not only standardization but also savings of time. The accuracy of determination has been improved by the development of immunoradiometric and immunoluminometric assays (19). Independence from angiotensinogen levels is another advantage of ARC determination. Plouin et al. (9) reported underestimated PRA levels in patients with liver cirrhosis and severe cardiac failure and overestimated PRA levels in women exposed to estrogens due to altered angiotensinogen levels. Valabhji et al. (20) described decreased PRA levels in type 1 diabetic patients, while similar concentrations of ARC in type 1 diabetics and volunteers were demonstrated (20). Reduced angiotensinogen levels in diabetic patients may be responsible for an underestimation of PRA (21). Because of the above-mentioned advantages the present study favors ARC over PRA for the diagnosis of primary hyperaldosteronism.

Differentiation of primary hyperaldosteronism from essential hypertension may be difficult. Most studies are therefore based on a population of hypertensive patients. However, increased diagnosis of adrenal masses due to improved imaging requires reliable parameters to separate primary hyperaldosteronism from pheochromocytomas, cortisol-secreting adenomas or incidentalomas. Thus, our study was performed with 
(A)

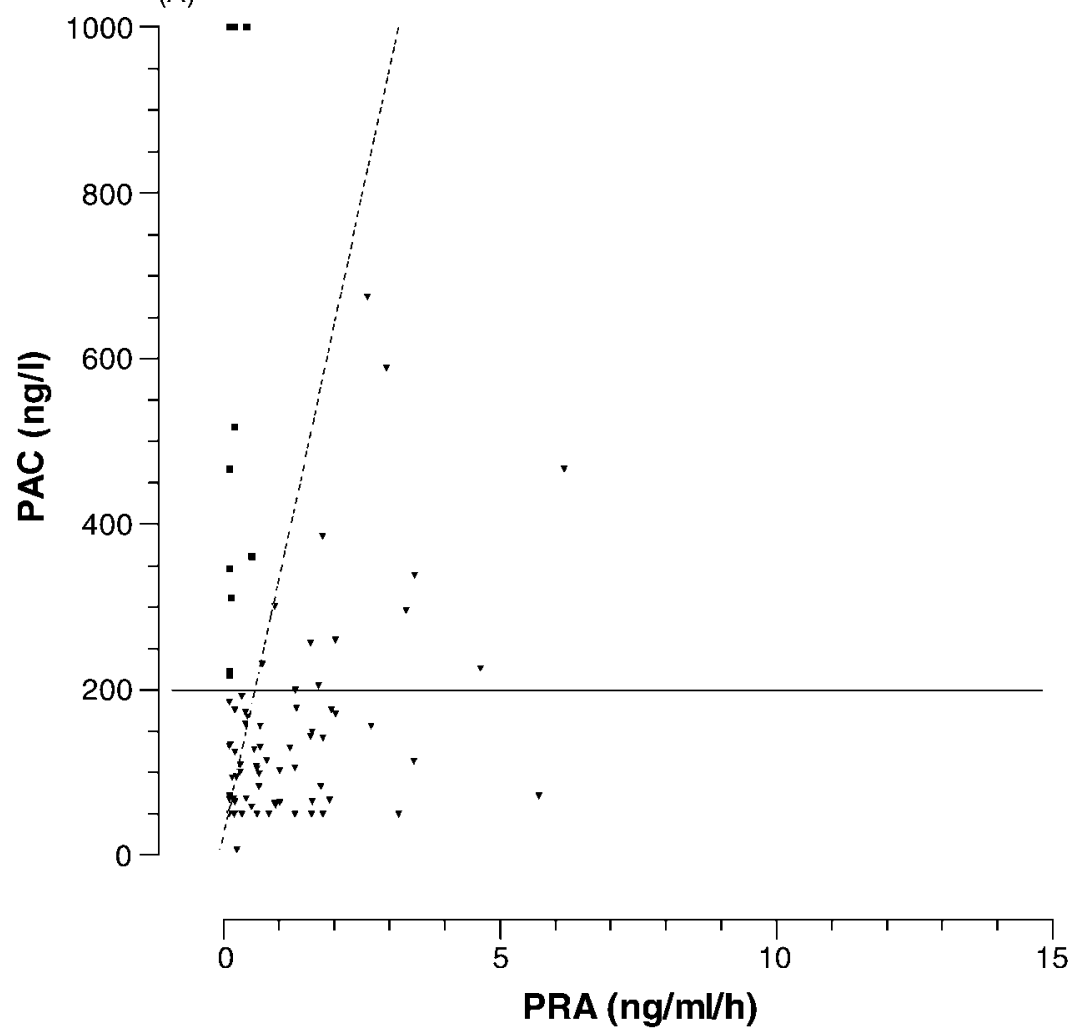

(B)

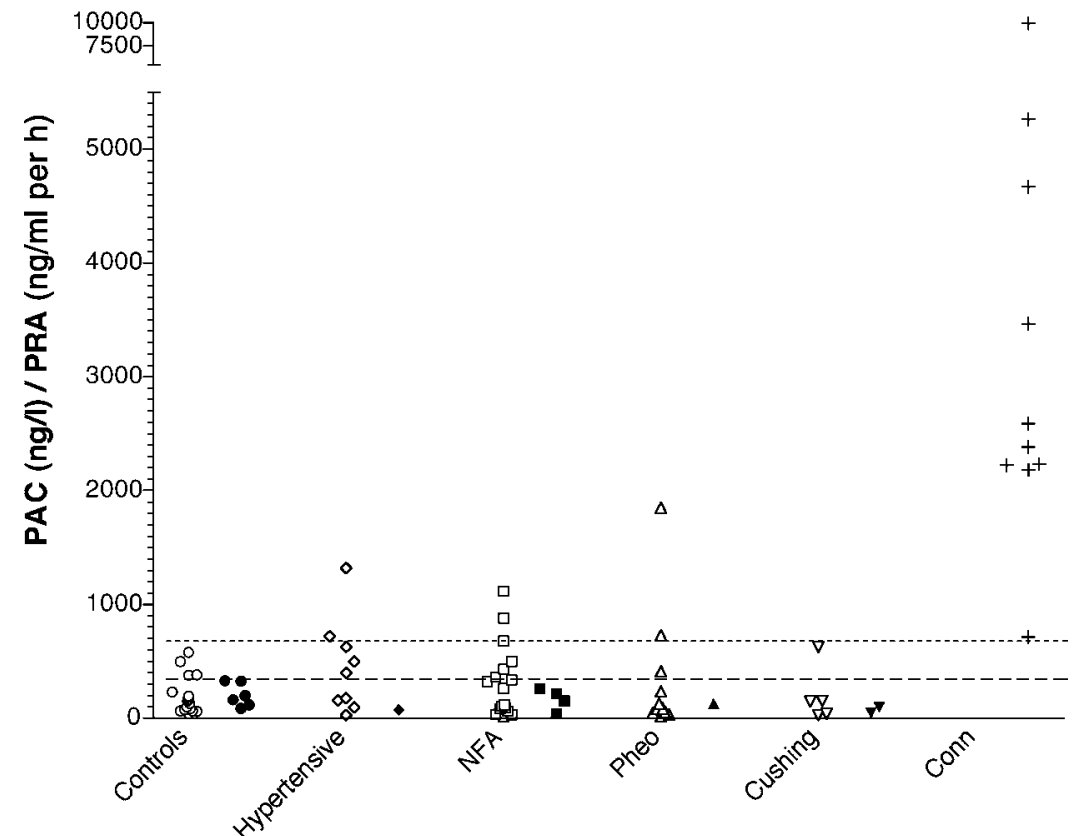

Figure 1 (A) Relationship of PAC and PRA in ten patients with primary hyperaldosteronism (squares) and 73 control subjects (triangles). The horizontal line shows the PAC threshold of $200 \mathrm{ng} / \mathrm{l}$. The upper left quadrant demonstrates the subjects positively screened for primary hyperaldosteronism. (B) PAC to PRA ratios in the different subgroups. The right column of each subgroup demonstrates the ratios of subjects with a PAC $\geq 200 \mathrm{ng} / \mathrm{l}$ (closed symbols). Open symbols demonstrate subjects with a PAC $\leq 200 \mathrm{ng} / \mathrm{l}$. + symbols demonstrate patients with aldosterone-producing adenoma. The upper horizontal line shows the ratio threshold of 680 for the diagnosis of primary hyperaldosteronism. The lower horizontal line shows the ratio threshold of 330 in subjects with a PAC $\geq 200 \mathrm{ng} / \mathrm{l}$. Pheo, pheochromocytoma; Conn, aldosterone-producing adenoma. 
(A)

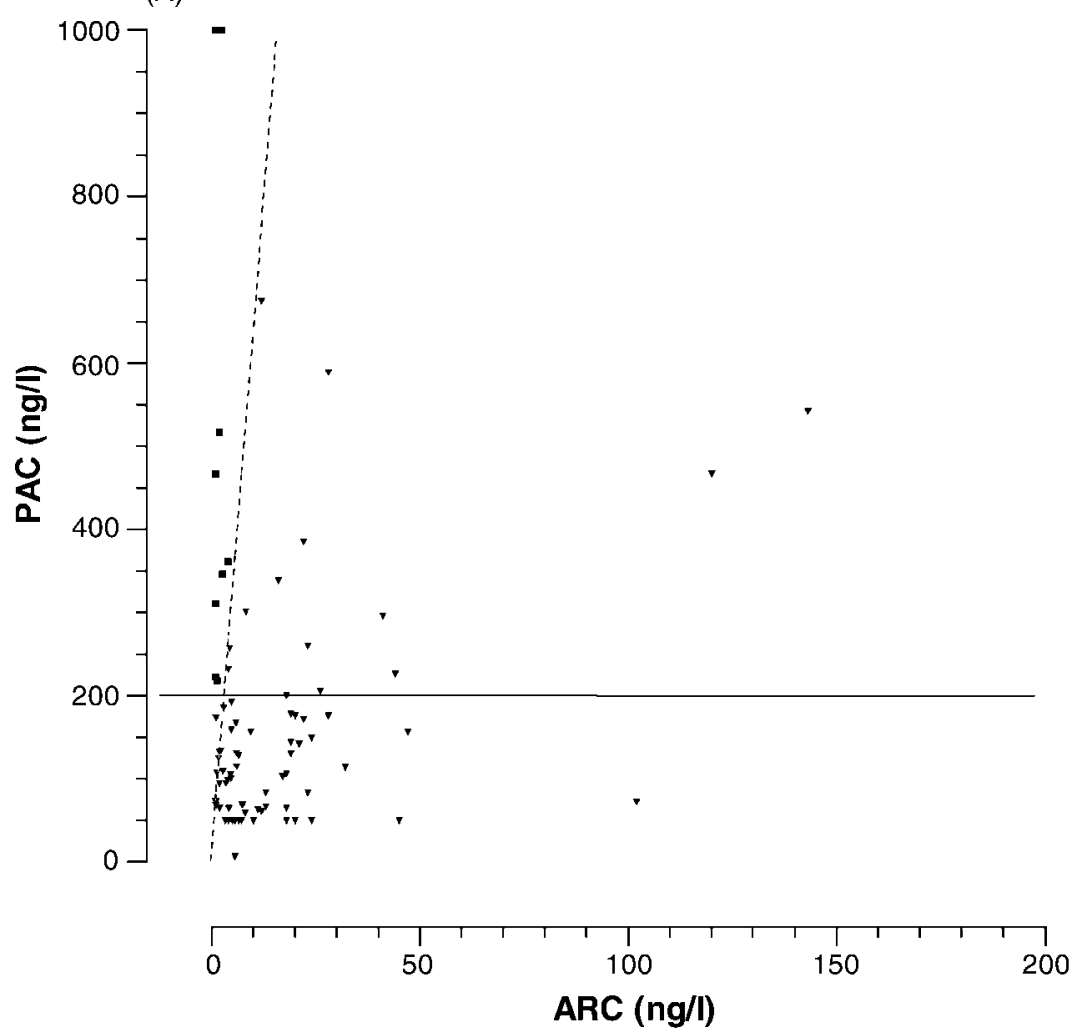

(B)

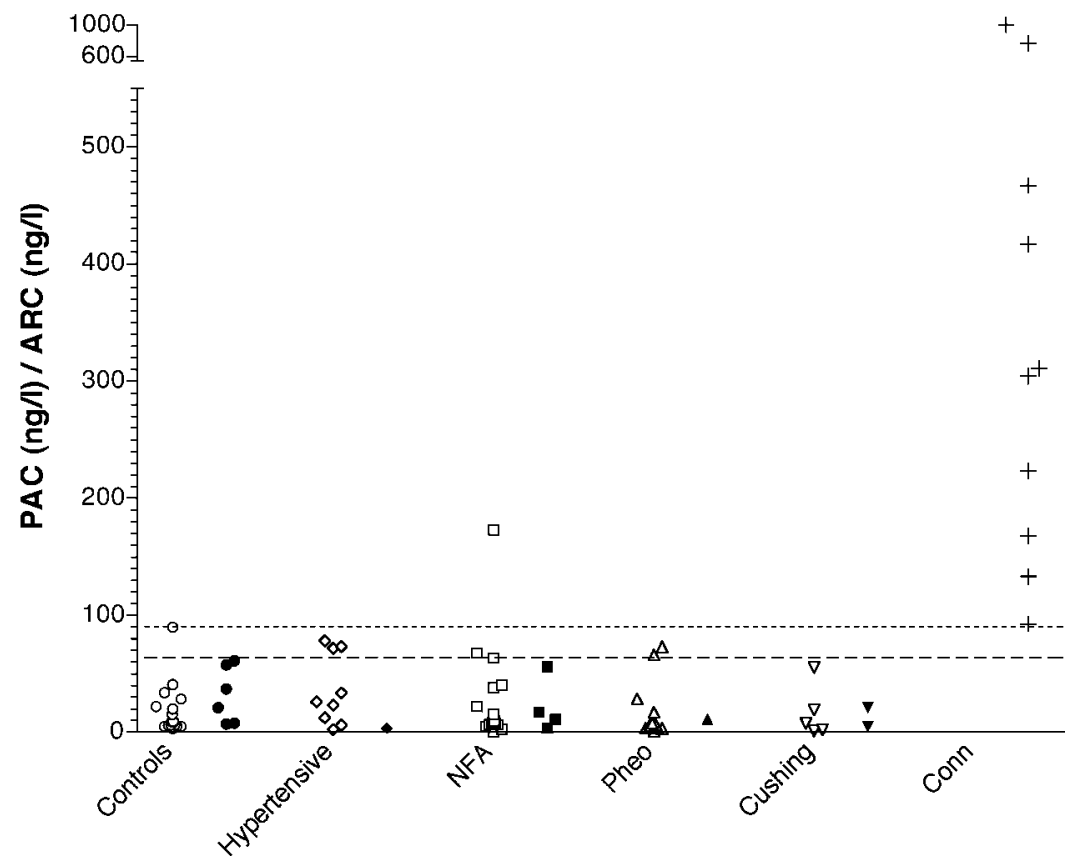

Figure 2 (A) Relationship of PAC and ARC in ten patients with primary hyperaldosteronism (squares) and 73 control subjects (triangles). The horizontal line shows the PAC threshold of $200 \mathrm{ng} / \mathrm{l}$. (B) PAC to ARC ratios in the different subgroups. The right column of each subgroup demonstrates the ratios of subjects with a PAC $\geq 200 \mathrm{ng} / \mathrm{l}$ (closed symbols). Open symbols demonstrate subjects with a PAC $\leq 200 \mathrm{ng} / \mathrm{l}$. + symbols demonstrate patients with aldosterone-producing adenoma. The upper horizontal line shows the ratio threshold of 90 for the diagnosis of primary hyperaldosteronism. The lower horizontal line shows the ratio threshold of 62 in subjects with a PAC $\geq 200 \mathrm{ng} / \mathrm{l}$. Pheo, pheochromocytoma; Conn, aldosterone-producing adenoma. 
special regard to a population of patients with adrenal masses of various etiologies. We provided a PAC to $\mathrm{ARC}$ ratio $\geq 62$ in patients with $\mathrm{PAC}$ levels $\geq 200 \mathrm{ng} / \mathrm{l}$ as a reliable screening method for primary hyperaldosteronism under random conditions.

\section{Acknowledgements}

We would like to thank Limbach Laboratory, Heidelberg, Germany, for their support in measuring active renin concentrations. We also thank Helmut Tourné for technical support.

\section{References}

1 Hiramatsu K, Yamada T, Yukimura Y, Komiya I, Ichikawa K, Ishihara $\mathrm{M}$ et al. A screening test to identify aldosterone-producing adenoma by measuring plasma renin activity. Results in hypertensive patients. Archives of Internal Medicine $1981 \mathbf{1 4 1}$ 1589-1593.

2 Gallay BJ, Ahmad S, Xu L, Toivola B \& Davidson RC. Screening for primary aldosteronism without discontinuing hypertensive medications: plasma aldosterone-renin ratio. American Journal of Kidney Disease 200137 699-705.

3 Loh KC, Koay ES, Khaw MC, Emmanuel SC \& Young WF Jr. Prevalence of primary aldosteronism among Asian hypertensive patients in Singapore. Journal of Clinical Endocrinology and Metabolism $2000852854-2859$.

4 Fishman LM, Kuchel O, Liddle GW, Michelakis AM, Gordon RD \& Chick WT. Incidence of primary aldosteronism uncomplicated 'essential' hypertension. A prospective study with elevated aldosterone secretion and suppressed plasma renin activity used as diagnostic criteria. Journal of the American Medical Association $1968205497-502$.

5 Distler A, Lommer D, Nast HP, Philipp T, Sinterhauf K, Walter U \& Lindmar R. Low renin hypertension. Contributions to Nephrology $1977869-80$.

6 McKenna TJ, Sequeira SJ, Heffernan A, Chambers J \& Cunningham S. Diagnosis under random conditions of all disorders of the renin-angiotensin-aldosterone axis, including primary hyperaldosteronism. Journal of Clinical Endocrinology and Metabolism 199173 952-957.

7 Tanabe A, Naruse M, Takagi S, Tsuchiya K, Imaki T \& Takano K. Variability in the renin/aldosterone profile under random and standardized sampling conditions in primary aldosteronism. Journal of Clinical Endocrinology and Metabolism $2003 \mathbf{8 8}$ 2489-2494.

8 Arnal JF, Cudek P, Plouin PF, Guyenne TT, Dussaule JC, Michel JB et al. Recent advances in the investigation of the renin-angiotensin and cardiac natriuretic systems in patients with chronic heart insufficiency. Archives des maladies du coeur et de vaisseaux 199184 $1273-1280$.
9 Plouin PF, Cudek P, Arnal JF, Guyene TT \& Corvol P. Immunoradiometric assay of active renin versus determination of plasma renin activity in the clinical investigation of hypertension, congestive heart failure, and liver cirrhosis. Hormone Research 199034 138-141.

10 Gordon DB, Sachin IN \& Dodd VN. Heterogeneity of renin substrate in human plasma: effect of pregnancy and oral contraceptives. Proceedings of the Society for Experimental Biology and Medicine $1976153314-318$.

11 Derkx FH, Steunkel C, Schalekamp MP, Visser W, Huisveld IH \& Schalekamp MA. Immunoreactive renin, prorenin, and enzymatically active renin in plasma during pregnancy and in women taking oral contraceptives. Journal of Clinical Endocrinology and Metabolism $1986 \mathbf{6 3} 1008-1015$.

12 Grumbach MM, Biller BM, Braunstein GD, Campbell KK, Carney JA, Godley PA et al. Management of the clinically inapparent adrenal mass ('incidentaloma'). Annals of Internal Medicine $2003138424-429$.

13 Lim PO, Rodgers P, Cardale K, Watson AD \& MacDonald TM. Potentially high prevalence of primary aldosteronism in a primary-care population. Lancet 199935340.

14 Blumenfeld JD, Sealey JE, Schlussel Y, Vaughan ED Jr, Sos TA, Atlas SA et al. Diagnosis and treatment of primary hyperaldosteronism. Annals of Internal Medicine $1994121877-885$.

15 Fardella CE, Mosso L, Gomez-Sanchez C, Cortes P, Soto J, Gomez L et al. Primary hyperaldosteronism in essential hypertensives: prevalence, biochemical profile, and molecular biology. Journal of Clinical Endocrinology and Metabolism 2000 85 1863-1867.

16 Weinberger MH \& Fineberg NS. The diagnosis of primary aldosteronism and separation of two major subtypes. Archives of Internal Medicine 1993153 2125-2129.

17 Seifarth C, Trenkel S, Schobel H, Hahn EG \& Hensen J. Influence of antihypertensive medication on aldosterone and renin concentration in the differential diagnosis of essential hypertension and primary aldosteronism. Clinical Endocrinology 200257 457-465.

18 Trenkel S, Seifarth C, Schobel H, Hahn EG \& Hensen J. Ratio of serum aldosterone to plasma renin concentration in essential hypertension and primary aldosteronism. Experimental and Clinical Endocrinology and Diabetes $200211080-85$.

19 Simon D, Hartmann DJ, Badouaille G, Caillot G, Guyenne TT, Corvol $\mathrm{P}$ et al. Two-site direct immunoassay specific for active renin. Clinical Chemistry 199238 1959-1962.

20 Valabhji J, Donovan J, Kyd PA, Schachter M \& Elkeles RS. The relationship between active renin concentration and plasma renin activity in Type 1 diabetes. Diabetic Medicine $2001 \mathbf{1 8}$ 451-458.

21 Sato Y, Hiwada K \& Kokubu T. Direct radioimmunoassay for human renin substrate and its measurement in plasma from essential hypertensive patients, diabetic patients and pregnant women. Japanese Circulation Journal $1984 \mathbf{4 8} 1236-1242$.

Received 8 August 2003

Accepted 17 December 2003 